\title{
Why Firms Fail to Sustain? Evidence from Dow Jones Index
}

\author{
Malik Muhammad Sheheryar Khan * Muhammad Muzammil Ghayas ${ }^{\dagger}$ \\ Sadaf Kashif $\ddagger$
}

\begin{abstract}
This study, focusing on the longevity of large business organizations as a period of uninterrupted satisfactory financial market performance, has examined companies failing to demonstrate longevity, such as by being removed from the Dow Jones Industrial Average index. The present research has performed group- and case-level longitudinal analyses of financial performance indicators. Afterwards, the qualitative longitudinal analyses were conducted based on primary qualitative data of sampled US organizations listed on the Dow Jones Industrial Average index across 28 years (1986-2013). This study has found that, from a longitudinal perspective, negative inflection points of concerted declines in the frequency with which different longevity factors are mentioned are highly likely to be among the anticipatory indicators for the financial events of removal of the corresponding companies from the Dow Jones index. In other words, this study indicates that organizational longevity is closely related to the dynamics of company-level financial and managerial performance.
\end{abstract}

\section{Introduction}

Risk has always remained the topic of discussion among the business community and the researchers; thereby researchers (Raza, Jawaid, \& Hussain, 2014) have rightly studied the risk and investment decisions. Researchers have studied the potential risks that arises from within the organizations and are controllable by the organization such as working capital management (Khan, Jawaid, Arif, \& Khan, 2012) as well as the risks that comes from the factors outside the organizations such as terrorism (Arif, Iqbal, Ali, \& Sohail, 2017). However, taking risk in the investment decisions is altogether different from the risks that challenge the very survival of a business organization. The question concerning the stock exchange related risk can be answered by portfolio diversification (Arif, 2017) . However, the question concerning the survival related risks have remained under researched. Therefore this study seeks to find the indicators whose presence or absence have contributed in leading the organizations towards the failure, especially in the firms that were performing well.

The basic motivation for this research study especially for studying the organizations that have been removed from the index is because of the fact that a number of researchers

\footnotetext{
${ }^{*}$ Iqra University, Karachi. E-mail: malik_sherry@yahoo.com

$\dagger$ Iqra University, Karachi. E-mail: muzammil.ghayas@iqra.edu.pk

‡Iqra University, Karachi. E-mail: sadaf.kashif@iqraisb.edu.pk
} 
have pointed to the fact that a lot of organizations fail to sustain even after having a very good start. In this regard, Montuori (2000) noted that almost $33 \%$ of the Fortune 500 companies in 1970 were not on the list in 1983 (i.e, after only 13 years). Foster and Kaplan (2011) noted that in the original Standard \& Poor's Index, which began in the 1920s, businesses lasted for 65 years on average. However, by 1998, a firm's predictable lifespan on the expanded S\&P 500 was reduced to 10 years. Foster and Kaplan (2011) highlight that approximately $15 \%$ of the sample of 1,008 US companies endured from 1962 to 1998. Collins (2001) studied 1,435 companies over three decades (1965-1995) and found that only $9 \%$ of them managed to outperform equity market averages for at least a 10 -year period. De Geus (2002) stated that multinational companies that were in the Fortune 500 usually existed for 40 to 50 years. De Geus (2002) also found that $40 \%$ of all new companies lasted less than a decade and one-third of the companies in the Fortune 500 index in 1970 were no longer in existence in 1983. Hence, the topic of organisational longevity is of crucial importance.

Focusing on longevity of large business organisations (Frye, 2000); this study argues that longevity can be construed as a performance-related phenomenon, rather than being seen only as a measure of the length of organisational survival. Hence removal of the firm from the Dow Jones Industrial Average index can be seen as the indicator of failure to sustain. It is for this reason that this study seeks to study the firms removed from the DJIA. Hence, this study significantly contributes the literature in a manner that it seeks to answer the question of longevity not only as the measure of lengthy of organisational survival but as the performance related phenomenon.

Limited scholarly attention has been paid to the longevity of large corporations (Lubinski, 2011). Moreover, the concept of corporate longevity is not adequately defined in scholarly literature (Wolfram \& Mohr, 2009). The impact of business strategy on longevity remains under-researched, due to the relative paucity of empirical studies that have addressed this interrelation (Voss \& Voss, 2000). This is especially the case if the definition of organizational longevity is broadened beyond the length of a company's existence (Mayfield, Mayfield, \& Stephens, 2007). While alternative approaches to organizational longevity exist, such as investigations of adaptations made by organizations to their environments from the perspective of organizational life cycle or ecology theories (Kasimoglu, 2006), the performance focus of the present study sets it apart from previous research concerned with the probability of companies ceasing to exist. In other words, alternative definitions of corporate longevity exist as well as empirical definitions, especially due to the long-standing disagreement in scholarly literature regarding the link between organizational performance and survival (Akin, 2000). According to Sanchez (2008), management is an important determinant of an organizations survival or non-survival.

Hence, this research will first seeks to examine the existing literature related to the organizational longevity, causal factors of organizational longevity and the internal factors of organizational longevity in the literature review. After discussing the literature, research philosophy and epistemology, sampling and data collection, validity and reliability are discussed in the research design. Whereas, the company level financial performance and the content analysis results are mentioned under the findings section. Lastly, discussions, recommendations, conclusions and limitations are mentioned in the last chapter of this 
research.

\section{Literature Review}

\section{The Concept of Organizational Longevity}

Frye (2000) defines organizational longevity as the length of survival of a self-governing organization without a market crash that ends trading. Davis (2014) stated survival is the ultimate performance measure. Peters, Waterman, and Jones (1982) search states that twothirds of the companies listed by Stacey (1992) as best practice examples have disappeared five years after release. Furthermore, Collins and Porras (1994) note that when CEOs wanted to benchmark against the best-run companies, they did not refer to fast-growing companies but to companies with long lifespans. However, high growth rates in the short term may not necessarily indicate organizational longevity in the long term, especially in relation to large companies and in rapidly changing economic environments (Demirbag, McGuinnness, Wood, \& Bayyurt, 2015). This raises the question of whether an organizations economic sustainability is primarily related to performing financially (Dechow, Ge, \& Schrand, 2010) . However, researchers are divided about whether financial stability accounts for organization long- or short-term success (Rothaermel \& Alexandre, 2009). Researchers continue to vouch for financial success as a means of purchasing innovative tools, which can make organizations successful, long-lived and sustainable in the competitive market (Rothaermel \& Alexandre, 2009). Johnson, Whittington, and Scholes (2009) agree that prioritizing financial obligations enables the attainment of other responsibilities.

Organizational perseverance over time can be affected not only by external, marketrelated factors but also by internal factors. Veider and Kallmuenzer (2016); Carr, Haggard, Hmieleski, and Zahra (2010) stated that organizations that suffer from non-survival owe their collapse to having created inappropriate objectives and goals and focusing too much on the past instead of focusing on the future. An organizations survival can, thus, be ensured only when the organization internalizes its need to survive as its foremost priority and applies methods that will provide beneficial outcomes in the future (Carr et al., 2010). Edwards (2010) also asserts that organizations that take their core business practices seriously are most likely to stand the test of time because they can attract and retain more customers.

Dunphy (2003) states that organizational sustainability is triggered by several factors, including leadership and strategic management coupled with the organizations adaptability to change whereas (Arif et al., 2017) studied the importance of Human capital. Morgan, Pritchard, and Pride (2011) also note that several resources apart from human resources contribute to organizational longevity. Weakness or failure of one of the components within an organization can result in the failure of the entire organization. The effective management of an organizations finances determines its economic sustainability. An organizations ability to sustain its bottom line determines the organizations future (Dechow et al., 2010). Thus, it can be emphasized that business systems are primary to an organizations financial obligations and must be aligned with the organizations financial objectives to achieve economic sustainability (Li, 2008). Johnson et al. (2009) noted that financial sustainability 
defines the core measure of an organization's ability to maintain relevance in the future. Researchers such as M. Porter (1996) also highlight the role of consumers in defining an organizations destiny by assessing the organization's value in satisfying consumer's needs. Wade and Recardo (2009) argue that financial viability is the ultimate measure of economic sustainability. Collins (2001) demonstrate that large global companies acknowledge both external and internal issues, ensure they have highly skilled leaders and can use and apply modern, innovative technologies and products, enabling these companies to ensure their endurance.

\section{Causal Factors of Organizational Longevity}

The organizational longevity or viability of business enterprises has been the subject of numerous empirical studies that have concentrated on causal factors, such as organizational resources, that are relevant to this phenomenon (Hoverstadt \& Bowling, 2005). Scholarly literature tends to agree that multiple characteristics exists that ensure the longevity of organizations and that they come from both the external environment and internal organizational systems (Britz, 2009; Cox, 2004) position is that, due to the constant change in external environmental factors in relation to marketing and global competency, organizations need to adapt internally to the demands of their environment. By changing internal factors such as strategies, designs and plans, companies can adapt to the needs of the business world. Embracing better business practices allows organizations to embrace new ideas, suggestions and a wide range of business opportunities (Linnenluecke \& Griffiths, 2010).

Sanchez (2008) states that an organization's longevity is determined by its dynamic response to changes that include both the external environment and an organization's internal factors. This can be achieved through a holistic approach where organizations should have appropriate goals and planning in place to align various stakeholders' interests while cultivating managerial skills (Sanchez, 2008) . Volgy, Sabic, Roter, and Gerlak (2009) argue that cultural understanding with appropriate structural arrangements and changes can also contribute to organizational longevity and development. Cox (2004) also asserts the importance of culture in an organization and highlights the importance of organizational provision of information, support and resources to employees as important criteria for an organization's durability.

According to Barney (1991), consistent financial performance in organizations creates longevity for present and future survival in the competitive market. A company that performs well financially and retains viability in the market is more likely to succeed in the long term (M. E. Porter \& Kramer, 2006). Johnson, Scholes, and Whittington (2010) concur that prioritizing financial obligations enables the attainment of other obligations, such as innovation. Redmon, Mawhinney, and Johnson (2013) also equate sustainability with long-term financial viability. They support their position through an assessment of organizations that have dominated technological transitional periods, and demonstrate that during such transitions, these organizations employed their financial abilities to retain their positions in the market (Redmon et al., 2013). Longevity allows organizations the possibility of detecting and correcting any deviations from desired goals (Hargreaves, 2007). 
Longevity also allows continuous improvements in other areas, such as business systems, to enhance quality standards (Ehnert, 2009), which allows changing the organization for the better in the present and future. And most importantly, longevity would require allowing the organization to change per changing technological developments, market demands, competition and regulations. Longevity in an organization can require adopting costeffective techniques, risk management strategies and encouraging stakeholder involvement, leadership and strategic management (Blackburn, 2012). However, longevity can be maintained and pursued by organizations through many essential factors. One such factor is good leadership skills that enable the organization to boost operating capacity and ensure adaptability in accordance with the business environment (Linnenluecke \& Griffiths, 2010). Leadership capability and skill can help organizations retain their longevity, for example, through developing strategic leadership roles that maintain the relationship between organizational structure and culture, properly maintain and use resources, adopt measures for adapting to change and ensure dynamic relationships with the board of directors. Once the organization's stability and longevity is maintained, longevity allows it to pursue goals that are possible and within the purview of organizational planning for the present and future (Dyllick \& Hockerts, 2002).

Several management systems have been designed by various analysts and management researchers to explain the longevity of organizations. However, a system and its evolving organizational structure will always be limited in its ability to capture the complexity of the system (Pawlowski, 2000). Thus, the problem occurs of how to design a list of key longevity factors that avoids the problem of intuitive ideas. External forces play an important role in organizational survival because organizations depend on the environment for resources (Maguire, 2003). The nature of an organization is to evolve over time towards a better fit with its environment, while when an organization does not fit into its environmental niche, it does not survive. Weisbord (1976) focuses on the organization and advocates viewing an organization from formal (organizational systems) and informal (organizational culture) perspectives.

\section{Internal Organizational Longevity Factors}

According to Waterman Jr, Peters, and Phillips (1980) productiveness and subsequently longevity are not simply conditioned by the organizational structure but involve the entire interrelationship between variables of structure, strategy, systems, style, skills, staff and superordinate goals. He further proposed that at a certain point in time if an organization does not maintain connectivity between structures and the other variables, the organization tends to break down. In 1921, DuPont was the first company to identify the importance of the interconnectedness of these variables. By 1970, $80 \%$ of companies listed in the Fortune 500 are believed to have followed this approach.

However, structure is not the only factor, as strategy acts as its associate. Strategy comprises all chosen routes of the organizations competitive success, and it involves all actions that a company or organization undertakes in the form of plans and methods for present survival, as well as for future needs that incorporate the requirements of the organizations, stakeholders and consumers (Nadler \& Tushman, 1980; Waterman Jr et 
al., 1980). All formal and informal procedures that enable organizations and companies to sustain ongoing daily activities are considered to constitute the organization's system. The term system broadly refers to procedures such as capital budgeting systems, training systems, cost accounting procedures and budgeting system (Waterman Jr et al., 1980). An efficient system guarantees an organization's effectiveness.

No organizational structure or system can function without leadership or workforce skills. Skills are the crucial attributes dominating capabilities in areas such as customer service, quality control, and innovation that differentiate an organization from its competitors (Palmer, Dunford, \& Akin, 2006). Skills allow companies to have visionary goals and determine present and future needs. Many companies obtain market recognition from what they do best, and marketing, structure and systems come along with this. Thus, skills capture the company's crucial attributes, and many multinational companies are known for what they deliver best and the global market they have captured. For example, since its foundation in 1911, IBM has been known for its? Prodigious customer service capabilities, or its sheer market power. Furthermore, strategy is considered the preeminent factor in playing an effective role in organizational development (Palmer et al., 2006). Strategy determines the organization's direction and is the fundamental element for success because strategies determine specific goals, objectives, values and missions the organization must pursue to ensure growth and development within the organization (Galbraith, 2008). Strategy obliges the organization to list and priorities its primary needs over its secondary needs.

The main function of structure is determining the location of the decision-making power and authority within the organizational framework (Galbraith, 2008). Through designing appropriate policies and strategies, human resource policies are responsible for producing effective employees and leaders in the organization because appropriate screening during the selection procedure allows them to groom employees to work towards organizational goals . Environment, resources, history and strategy are likely to influence the organization in its performance against rival companies in the market, which makes these factors vital in conditioning organizational functioning and longevity (Nadler \& Tushman, 1980). Environmental forces place market pressure on the organization, since it can constrain organizational production and functioning by imposing threats and regulations (e.g. through imposed regulation by government bodies) or technological constraints (Palmer et al., 2006), even though it can also provide innovation opportunities for the organization .

Factors such as human resources, technological and financial capital, information, raw materials, brand and premium value of the organization in the market (Barney, 1991) help organizations determine to what extent their resources remain flexible or inflexible when considering operations and new ventures. Resources also help determine which parts or types of resources the organization can deploy to ensure strength for organizational longevity. Learning from past mistakes, crises or strengths can help business organizations make appropriate decisions. In many successful organizations, important key strategic decisions such as appointing leaders, recruiting employees and decision making for change are determined by reflecting on the organizations history (Nadler \& Tushman, 1980). Strategy creation and strategy management include considering all other factors to formulate plans and policies for organizational growth and development. Ensuring effective output 
can be expected to guarantee organization's longevity, while ineffective output is likely to compromise the organization's functionality (Nadler \& Tushman, 1980).

De Geus (2002) refers to companies as organisms that should be willing to change to survive. Organizations are always evolving and searching for new ways of innovating to ensure an advantage over competitors (Martins \& Coetzee, 2009). If an organization establishes only strategies, motives or a mission without effective leadership, the mission or strategies cannot succeed. Thus, effective leadership is required to enforce the mission and strategy, which are in turn affected by the cultural change of the internal environment. Apart from strategies, motives and culture, other variables exist such as structure, management practices, systems and work unit climate, which motivate employees to achieve productive performance and organizational change. Yet, strategy can lay the foundation for achieving mission statement objectives over an extended time scale (Burke \& Litwin, 1992), so that strategy does not refer to performance but to longevity.

Haugh and Talwar (2010) stated that, organizational economic sustainability results from a wide variety of factors. Hubbard, Pocknee, and Taylor (1996) stated that organizational capabilities depend on certain factors, which are culture, structure, systems, human resource capacity and financial resources. Pawlowski (2000) indicated that to sustain itself, an organization must be stable, continuous and long lived. While Hubbard et al. (1996) did not emphasis an organization's longevity. Pawlowski (2000) noted the importance of longevity by studying changes in the external environment; however, he did not discuss factors that contribute to organizational longevity. Furthermore, as per Montuori (2000) organization's ability to instigate changes enables longevity and sustainable growth. Continuous change with the changing dynamic environment can be considered an important factor that contributes to overall organizational sustainability. Mitleton-Kelly (2006) noted that when an organization does not adapt itself to the changing environment, it risks becoming obsolete. Miller and Hartwick (2002) state that companies that cannot instigate change within a timely period risk failure. An organization's reluctance to change per the changing external environment is at risk of failure. According to Mayfield et al. (2007), organizations that have a prospector strategic approach have lower levels of longevity than organizations that employ a defensive strategic approach. The corporate sustainability is a result of sensitivity to the dynamic environment, cohesion and the organization's identity, tolerance and flexibility to change within and outside the organizational system, and the use of conservative financing. Moreover, Harrington (2006) identifies five factors that contribute to organizational excellence, which are process management, project management, change management, knowledge management and resource management. Organizational longevity is, thus, a multidimensional phenomenon that is not reducible to a single causal factor (Pawlowski, 2000).

\section{Research Design}

The primary research proposition of this study is that the characteristics of the group removed from the Dow Jones can be expected to demonstrate low levels of the critical factors theorized to be essential for a long-term presence on the Dow Jones index. The 
research design chosen to test these propositions is a multiple, longitudinal case study.

\section{Research Philosophy and Epistemology}

Since the study seeks to connect across-case variation with previous theoretical knowledge, therefore the study follows the comparative case study methodology (Vannoni, 2015). This corresponds to the middle range theory development method, based on comparative typologies of empirical cases with relatively similar characteristics (George, Bennett, Lynn-Jones, \& Miller, 2005). The advantage of this philosophical approach is that the outcomes of the present research are not over-determined by its theoretical premises, which reduces the risk of falsely rejecting research propositions (Vannoni, 2015). The present research is concerned with formulating propositions restricted to providing empirically-backed explanations to the variation in data collected from case studies that are sufficiently similar to warrant their comparison (Elman, 2003). Hence, the conclusions of comparative case study analyses have limited generalize ability beyond cases that are similar in their characteristics to the research sample (King, Keohane, \& Verba, 1994). Yet, comparative methods make inferences from several representative cases through the application of rigorous and replicable analytical procedures (Brady \& Collier, 2010).

\section{Research Methodology}

The principal method used in the research is the content analysis of the mentioned documents. The qualitative data collected from these documents have been analyzed using NVivo software. The primary results of this content analysis have been formalized in quantitative form. The results of the NVivo-aided content analysis have been manually checked for consistency with the theoretical definitions of the corresponding longevity factors. Frequencies of each longevity factor have been computed. Additionally, financial index information has been analyzed. Especially since removal from the DJIA does not always imply that companies in question have failed to survive, therefore, a longitudinal analysis of these financial indicators has been performed to examine the research proposition.

\section{Sampling and Data Collection}

Due to their amenability for comparative studies of internal organizational factors that lead to sustained company performance, financial indexes are increasingly used as empirical indicators of economic sustainability (Slager, 2015). Following Frye (2000) research approach, some studies select their research objects due to their membership in stock indices or other listings, such as the Fortune 500 list. Foster and Kaplan (2011), examined longevity based on the Standard \& Poor's Index (S\&P). The Dow Jones Industrial Average (DJIA) index as a listing of large, publicly traded organizations, is a widely accepted and utilized benchmark for corporate performance, due to its public information availability, externally verified selection process and yearly reviewed selection methodology (Knoepfel, 2001). Thus, the DJIA is a fitting source of empirical information for the present study. 
The 30 largest or best-performing companies listed on this Wall Street index are the leading world companies. This list of these companies, which is regularly revised, has existed for almost 150 years (S\&P 2015). The companies in the DJIA are known as blue-chip companies not only because of their ability to generate money but also because of their stability and longevity (S\&P 2015). Many companies listed in the DJIA have demonstrated that they rely on their capabilities, allowing them to survive longer than many other companies. Thus, Collins (2001) based their study on corporate longevity mainly on examples from the Dow Jones. Similarly, the current research is also based on the examples from the DJIA index. Five companies namely Alcoa, Altria, AT\&T, Eastman Kodak and Goodyear that were listed on the DJIA on 1 January 1986 but were no longer listed on 7 July 2014 were the sample of this study.

Selection of these companies was based on the availability of primary data. The period of 28 years was selected because it is sufficient to include different types of events that may have forced the company to re-evaluate its strategies. This research has not used primary data collection methods involving human subjects, such as interviews or surveys to avoid subjectivity bias (Bygrave, 2007). The empirical data used were collected from formal company statements, including annual corporate reports, chairperson's reports and standardized financial reports of the large companies sampled for the research. These documents were selected because company reports are considered credible and accurate data sources that provide information about a company's status, values and concerns, as well as their actions in the conduct of their business. Public companies annual reports are regulated by legislation that requires the reports to provide accurate information about events that may have occurred in the company during the period covered by the report. Thus, the companies' legal documents were considered the most reliable sources of information (Kaplan, 2008).

The primary qualitative data, the annual reports of the selected large companies as case studies were initially analyses using content analysis technique through NVivo software package. This enabled an absolute and relative assessment of the degree to which different organizational longevity factors are present in company reports and press releases. Likewise, quantitative company performance data have been used for exploring group- and company-level economic performance dynamics, such as inflection points in financial indicator longitudinal dynamics that have led to the removal of sampled companies from the Dow Jones index. The aim of content analysis is to reduce the existing complexity of the empirically investigated material (Schreier, 2012). In this study, this is achieved by frequency analysis of keywords reflecting the descriptors of longevity. In the initial stage of the study, the absolute and relative frequencies with which theory-determined longevity factors appear in the primary empirical data have been determined based on keywords with the help of which factors were operationalized. Organizational factors explaining large enterprises longevity identified in the literature review, are innovative capability, organizational resources, organizational culture, strategic management, and organizational systems. These factors are the basis for coding the corporate content from the annual reports analyses with NVivo. The list of descriptors was created based on these five factors. This allowed for a more encompassing content analysis and is in accordance with content analysis methodology (Krippendorff, 2018). The content analysis was conducted 
using word frequencies of following 17 descriptors of five factors of longevity as outlined in Table 1.

\begin{tabular}{|c|c|}
\hline Key Elements & Descriptors \\
\hline Innovative Capability & "Innovation,Design,Research \\
\hline Organisational Resources & Human Resources, Cash Resources \\
\hline Organisational Culture & Culture,Values, Vision, Mission \\
\hline Strategic Management & $\begin{array}{l}\text { Strategy,Competitive Advantage, } \\
\text { Core Business, Goals, Objectives }\end{array}$ \\
\hline Organisational Systems & Systems,Productivity, Quality \\
\hline
\end{tabular}

Furthermore, it was checked manually that the word was used in the relevant context. In this study, the data collection period has been determined on a case-by-case basis from the beginning of research period to the year researched for companies were removed from the DJIA.

\section{Validity and Reliability}

The internal validity of this research is maintained through the instrumentation and selection of well-established research methods (Bazeley \& Jackson, 2013). Present empirical results are obtained, (Krippendorff, 2018) recommendations, through a proper study design, strict protocol execution, and compliance with the National Australian Guidelines for Research Ethics. To ensure data reliability of the NVivo content analysis data, a manual check-coding activity was conducted. To ensure the coders' understanding of this research, a set of explicit recording instructions was developed and communicated. As the research is based on publicly available data, there are no issues relating to research involving human subjects or privacy.

\section{Data Analysis Procedures}

In this research, the term frequency refers to the number of times a word appeared in the case study company's official documents (House, Spangler, \& Woycke, 1990). This research has used the frequency of the use of each descriptor within each factor in relevant documents, to determine the corresponding year-by-year and factor-by-factor frequencies for each company. As the documents varied in length from year-to-year and from company-tocompany, the frequencies were divided by number of pages to make the results comparable.

As part of comparative case study analysis, the present research has also performed quantitative group- and case-level longitudinal analyses of financial performance indicators. Thus, on the level of the organizations removed from the Dow Jones index, descriptive and trend-line comparisons of the respective profitability ratios, efficiency ratios, liquidity ratios, leverage ratios and market value ratios have been performed. Profitability ratios comparisons have examined the longitudinal dynamics of profit margins, returns on assets, and returns on equity. Efficiency ratios analyses have compared asset turnover ratios and returns on capital employed. Liquidity and leverage ratio analyses have demonstrated the comparative dynamics of the variation in current ratios, times interest was earned and 
debt to equity ratios. Market value ratio comparative analyses have concentrated on the time series dynamics of price-earnings ratio trends and dividend yield trends in each of the researched groups.

Given that company-level analyses of longitudinal dynamics of their financial indicator variations have been performed regarding yearly sales, profit margins, price to earnings ratios, dividend yields, corresponding empirical findings have indicated the presence of inflection points in the dynamics of these indicators that have preceded the removal of researched companies from the DJIA. Especially since in this research, organizational longevity has been operationalized in financial performance-related terms as a prolonged presence on the Dow Jones index, these longitudinal analyses of financial indicators enable the triangulation of empirical data. Given that company reports only provide secondary information about the longevity factors suggested by scholarly literature, these longitudinal analyses enable an independent verification of the research proposition within the framework of the multiple case study method.

\section{Findings}

In all, findings are to be discussed related to five organizations studied in this study, below are the research findings regarding each of the firm:

\section{Alcoa}

Alcoa (Aluminium Company of America) is a global leader in lightweight metal technology, engineering and manufacturing and is working towards providing innovative solutions. Alcoa's removal from the DJIA index came about as sales and profits plummeted in 2013.

\section{Company-Level Financial Performance Indicators}

The removal of Alcoa from the DJIA in 2013 was preceded by continuous, even though variable, decline in sales, profit margins, price earnings ratio and dividend yield. It is notable that removal from this index did not immediately follow sharp declines in these financial performance indicators but only after several years of low and declining performance. The financial charts demonstrate that the inflection point immediately preceding its removal from the DJIA index was sharp declines in profit margin and price earnings ratio in the two years before this event. This has occurred on the background of declining sales from 2006 to 2013 with a brief upward trend between 2009 and 2011. In the period preceding the inflection point, Alcoa's profit margins and dividend yields have exhibited a sharp dive between 2008 and 2010, while its price earnings ratios significantly declined between 2006 and 2008 as well as between 2009 and 2011.

\section{Company-level Content Analysis Results}

Qualitative analyses of Alcoa show that, based on weighted average frequencies, three out of five factors (i.e.organizational culture, systems and strategy) exhibited declining 
frequencies of corresponding keywords in company reports in two years immediately before its removal from the index (2012-2013). Not only all weighted average frequencies of factors have demonstrated cross-cutting declines in the years 2006-2007 but also, based on absolute frequency counts, four out of five factors have demonstrated consistent frequency declines in the run up to this event, such as in the years 2006-2008 (i.e. organizational culture, systems, resources and innovative capability) and four out of five factors have shown coordinated frequency drops between 2010 and 2011 (i.e.organizational culture, systems, organizational strategy, and innovative capability) on the basis of their weighted average frequency estimates.

\section{Altria}

Altria (previously Philip Morris Companies, Inc.) occupies a leading position in the US tobacco industry. Initially named the Phillip Morris Group, it changed its name to Altria in 2003.

\section{Company-level Financial Performance Indicators}

The termination of continued existence as a publicly traded company under the brand name Phillip Morris has been preceded by generally declining financial performance, as demonstrated by sales, profit margins, price earnings ratios and dividend yields in the two years immediately preceding its reorganization and rebranding as Altria in 2003. It appears that its concerted declines in sales and dividend yields have constituted the inflection point that has led to the removal of this company from the DJIA. Specifically, while Altria's sales have been stagnant in the years 2000-2001 and steeply falling between 2001 and 2003, price earnings ratios have largely followed this trajectory in the period between 2000 and 2003, whereas dividend yields have been markedly declining in the years 2001-2003, and so was the case of net profit margins. These developments have apparently contributed to the inflection point dynamics.

\section{Company-level Content Analysis Results}

In concert with findings concerning Altria's financial performance indicators, content analysis results show a cross-cutting inflection point in the frequency with which keywords related to longevity factors appear in company reports. In the years 2000-2002 leading to the removal of Altria from the Dow Jones index, four out of five longevity factors (i.e. organizational culture, systems, resources, and strategy) have exhibited either declining or unchanging keyword frequencies, based on their weighted average estimates. Furthermore, in the years 2001-2003 both the weighted average and absolute frequencies of three out of five longevity factors have either remained unchanged or continued to decline in organizational culture, systems and resources. These dynamics have constituted the inflection point momentum that is hypothesized to be behind this company's removal from the Dow Jones index. 


\section{AT\&T}

AT\&T was established in 1885 as the Bell Company and currently offers voice coverage, data roaming and mobile telecommunication services. It was acquired by SBC Communications in conjunction with its removal from the DJIA in years 2004-2005 S\&P Dow Jones Indices.

\section{Company-level Financial Performance Indicators}

AT\&T's acquisition by SBC in 2004-2005 that interrupted its continuous trading on stock exchange during this period was preceded by a high degree of volatility in performance indicators movements. AT\&T's removal from the DJIA was preceded by a two-year period of sales and profit margins declines in the years 2001-2002 with rebounding performance in the run-up to 2004 on the background of relatively flat price earnings ratios between 1996 and 2006. The inflection point with which its removal from the DJIA index can be associated is volatile and declining sales figures, profit margins and dividend yields in the years 2003-2005.

\section{Company-level Content Analysis Results}

In correspondence to the financial indicators of AT\&T, it is clearly discernible that weighted average keyword frequencies indicate that in the years 2002-2004, an inflection point of declining relative frequencies developed across two of the five longevity factors (i.e., organizational culture and systems). Additionally, in the period 2003-2004 that immediately preceded the removal of AT\&T from the DJIA index, weighted average frequency counts of the presence of longevity factor keywords show that four out of five factors (i.e.organizational culture, systems, strategy and innovative capability) have exhibited consistent declines in their relative frequency. Absolute frequency counts of longevity factors indicate negative dynamics of the same scope, even though different longevity factors (i.e., systems, resources, strategy and innovation) have demonstrated concerted declines, and of the same scale, albeit with a one-year lag, given that this inflection point dynamics applies to the years 2004-2005 only. These inflection points are observable across both weighted and absolute estimates of presence of longevity factors closely following performance indicator dynamics in same period.

\section{Eastman Kodak}

Eastman Kodak is a US technology company providing imaging solutions and services in business. Kodak was removed from the Dow Jones index in 2004 after its announcement that it would stop selling film cameras in Europe and North America.

\section{Company-level Financial Performance Indicators}

Kodak's financial performance, indicates that its removal from the Dow Jones index in 2004, due to its reorganization, has primarily been provoked by sharp to moderate drops in sales 
(2003-2009), profit margins (2004-2005 and 2007-2009), price earnings ratios (2003-2005 and 2007-2009) and dividend yields (2007-2009) in the years preceding this event. This constituted the inflection point in the movements of these financial indicators, which is clearly associated with the company's withdrawal from the DJIA index, which took place in the background of long-standing volatility across its different performance indicators. This event has also presaged Kodak's bankruptcy proceedings and delisting from NYSE in 2012.

\section{Company-level Content Analysis Results}

Similar to findings based on performance indicator movements, negative momentum has been developing in the years 2004-2005, as four out of five longevity factors (i.e. organizational culture, systems, resources and strategy) have exhibited consistent declines both in their weighted average frequencies and in their absolute count frequencies. However, for Kodak, it appears that the decisive inflection point occurred the year before its removal from the index as, based on weighted average frequency assessments, all five longevity factors have demonstrated either declining or unchanging levels in the years 2007-2008. It is notable that, in the same period, absolute counts of the longevity factor presence in company reports show that negative momentum leading to this inflection point was only slightly narrower in scope, since it encompassed the estimate of only four out of five longevity factors (i.e. organizational culture, systems, resources and innovation) that have either declined or remained stagnant. In their scope, these coordinated declines echo those that have occurred in the years 2004-2005. This indicates that qualitative content analyses have indicated the presence of inflection points in the dynamics of longevity factor reporting in company-related publications.

\section{Goodyear}

Goodyear manufactures tyres for automobiles. Goodyear was removed from the Dow Jones in 1999, after it recorded one of its worst years in profit performance.

\section{Company-level Financial Performance Indicators}

Goodyear's financial indicators demonstrate that, in the research period, primarily its volatility and negative financial performance in the preceding years led to its removal from the Dow Jones index in 1999. While in the previous year, its sales and dividend yields have demonstrated moderate recovery, 1998 clearly serves as the inflection point for Goodyear's removal from the DJIA index, since in this year, its profit margins and price earnings ratios experienced sharp drops. These developments have also provided a backdrop for the reorientation of Goodyear's activity, with the help of international joint ventures in Europe, North America and Japan as well as an alliance in 1999 with Sumitomo Rubber Industries based in Japan. 


\section{Company-level Content Analysis Results}

Similar to the clear downward momentum across different financial performance indicators that led to Goodyear's removal from the Dow Jones index, qualitative content analyses indicate that both weighted and absolute counts of keyword frequencies have exhibited at least two year-long declines in the run-up to this event across four out of five longevity factors in the years 1998-1999, even though different frequency estimates show these declines across dissimilar sets of longevity factors. This, from 1998 to 1999, weighted average frequencies have indicated that only the factors of culture, systems, resources and strategy have declined. By contrast, in the same period, absolute counts indicate that while culture, systems and strategy have decreased in frequency, resources have remained unchanged. This demonstrates the presence of an immediately preceding inflection point in longevity factor frequency dynamics in Goodyear's corporate reports that led to its delisting from the DJIA.

\section{Cross-company Findings}

\section{Cross-company Financial Performance Indicators}

This study indicates that all researched companies have been removed from the DJIA index following the inflection points of negative performance and longevity indicator dynamics they experienced. Even though the years in which researched corporations were removed from the index are not identical, the aggregate movements of their financial indicators, demonstrate the presence of cross-cutting inflection points as a characteristic of the organizational performance dynamics that financial data for individual companies have also exhibited. Furthermore, given that in several cases the removal from the index has followed an inflection point of negative financial performance leading to company reorganizations, the presence of coordinated negative movements across several financial performance indicators throughout the research period might explain the lacking longevity of these corporations. In other words, while some of the companies removed from the index have returned to the financial market after significant changes in their organizational structures, the periodic re-appearance of cross-cutting inflection points seems to characterize these companies as a group. Thus, in this group, falling sales figures have largely overlapped with declining profit margins and dividend yields in the periods from 1996-1997, from 2001-2003 and from 2007-2009.

\section{Cross-company Content Analyses Results}

The comparison of innovative capacity, organizational resources, organizational culture, organizational strategy and organizational systems factors dynamics across all companies removed from the Dow Jones index demonstrates that the event of their removal from this index has been preceded by prolonged periods during which the frequency of innovative capacity has either consistently declined or remained below average levels across several years. These periods range from 4 to 9 years for innovative capacity, from 4 to 14 years for 
organizational resources, from 3 to 11 years for organizational culture, from 2 to 10 years for organizational strategy and from 2 to 12 years for organizational systems.

\section{Conclusion}

Alcoa tried to be innovative yet it failed to implement the strategies it made. The supply demand imbalances in the resource element. The initial lack of pro activeness in organizational culture element and the severe turmoil in the productivity element made it difficult for Alcoa to remain competitive and was removed from the index. Whereas, in the case of Altaria, there was an initial lack of vigor in the innovation element and the importance of organisational culture was not recognized as it has not been discussed till the year 2001 . On the other hand, the AT\&T had a strong record of innovation but its strategies were not particularly successful at first as the earnings were flat and the cost of operations was too high. The Eastman Kodak was focusing on innovation and technology however innovations were not discussed until the late 1990's and no emphasis was given to organizational culture till early 2000's. Last but not the least, the Goodyear was focusing on innovation but their cash flows were not steady and culture was not discussed.

This study has provided an empirically supported answer to its primary research question, since its comparative analyses have indicated that longevity factor keyword frequencies closely correspond in their longitudinal dynamics to financial performance indicators. The companies removed from the DJIA index have demonstrated multiple-factor, sometimes multi-year inflection points of the falling frequencies with which organizational factor keywords receive mention in primary documents. Since these companies have exhibited negative inflection point dynamics of falling keyword frequencies over more than one year and cutting across at least three longevity factors, these findings tentatively validate the definition of organizational longevity as a performance-related construct that has been adopted in this study.

As in the case of financial performance indicators, close correspondence in presence of the inflection point dynamics or lack thereof has been found between weighted average frequencies and absolute keyword counts across the researched companies. Since not all corporations removed from the index have ceased to exist, as some of them have re-emerged on the financial market after reorganizations, acquisitions or governmental bailouts, all available qualitative information across the entire research period has been used. From the longitudinal perspective, negative inflection points of concerted declines in the frequency with which different longevity factors are mentioned are highly likely to be anticipatory indicators for the financial events of the removal of the corresponding companies from the index. Thus, a consistent absence of multiple-factor inflection points of falling frequencies can be hypothesized to be a primary indicator of corporate longevity. These findings of this study consistently demonstrate that companies removed from the Dow Jones have been characterized by high levels of financial indicator volatility and cross-cutting negative performance before their removal from the index.

This study suggests that it is not only access to managerial skills, technical expertise and financial resources that contributes to organizational longevity, but also consistently 
high levels of attention to these factors that ensure the continued presence of publicly traded companies on the DJIA. Therefore it is recommended that organizations should focus on efficient utilization of managerial skills, technical expertise and financial resources. Furthermore, this study also suggests that regardless of a corporation's time in the financial market, the multiple-factor and protracted disregard to longevity factors can be expected to be associated with negative financial performance and removal from leading market indices, such as the Dow Jones index. Thus, the study findings reinforce (Davis, 2014) construal of organizational survival and longevity as performance-related construct.

In other words, this study indicates that organizational longevity is closely related to the dynamics that company-level financial and managerial performance exhibits. The organizational longevity derives from the dynamic characteristics of financial and organizational performance, such as presence or absence of multiple-factor inflection points. Especially since this study has employed multiple-case and comparative research design, this study may claim that its findings have generalizable.

The primary limitation of this study is that the research examined only companies listed on NYSE and NASDAQ. Thus, the replication of the present research design in relation to leading financial indicators in the stock markets in other countries may produce results and conclusions that are different than those of the present study. Furthermore, the present research conducted on the sampled companies could have been broader. In correspondence to the definition of organizational longevity adopted in this study, the DJIA has served as a longevity indicator, which limited the population of the companies that could be sampled. 


\section{References}

Akin, G. (2000). How long do things last? Journal of Organizational Change Management, 13(1), 30-31.

Arif, I. (2017). Terrorism and stock market nexus: New evidence from wavelet analysis. South Asian Journal of Management Sciences, 11(2), 94-107.

Arif, I., Iqbal, A., Ali, S. F., \& Sohail, A. (2017). International stock market diversification among BRICS-P: A cointegration analysis. Journal of Management Sciences, 4(2), 269-285.

Barney, J. (1991). Firm resources and sustained competitive advantage. Journal of Management, 17(1), 99-120.

Bazeley, P., \& Jackson, K. (2013). Qualitative data analysis with NVivo. United States: Sage Publications Limited.

Blackburn, W. R. (2012). The sustainability handbook: The complete management guide to achieving social, economic and environmental responsibility. United Kingdom: Routledge.

Brady, H. E., \& Collier, D. (2010). Rethinking social inquiry: Diverse tools, shared standards. United States: Rowman \& Littlefield Publishers.

Britz, M. T. (2009). Computer forensics and cyber crime: An introduction, 2/e. Pearson Education India.

Burke, W. W., \& Litwin, G. H. (1992). A causal model of organizational performance and change. Journal of Management, 18(3), 523-545.

Bygrave, W. D. (2007). The entrepreneurship paradigm revisited seventeen years later. Edward Elgar, Northhampton.

Carr, J. C., Haggard, K. S., Hmieleski, K. M., \& Zahra, S. A. (2010). A study of the moderating effects of firm age at internationalization on firm survival and short-term growth. Strategic Entrepreneurship Journal, 4(2), 183-192.

Collins, J. (2001). Why some companies make the leap and others don't. Good to great. New York: Harperbusiness.

Cox, R. J. (2004). No innocent deposits: Forming archives by rethinking appraisal. USA: Scarecrow Press.

Davis, I. (2014). Reflections on corporate longevity. McKinsey Quarterly, 3(3), 118-122.

Dechow, P., Ge, W., \& Schrand, C. (2010). Understanding earnings quality: A review of the proxies, their determinants and their consequences. Journal of Accounting and Economics, 50(2-3), 344-401.

De Geus, A. (2002). The living company. Harvard Business Press.

Demirbag, M., McGuinnness, M., Wood, G., \& Bayyurt, N. (2015). Context, law and reinvestment decisions: Why the transitional periphery differs from other post-state socialist economies. International Business Review, 24(6), 955-965.

Dunphy, D. (2003). Corporate sustainability: Challenge to managerial orthodoxies. Journal of Management and Organization, 9(1), 2-11.

Dyllick, T., \& Hockerts, K. (2002). Beyond the business case for corporate sustainability. Business Strategy and the Environment, 11(2), 130-141. 
Edwards, M. (2010). Organizational transformation for sustainability: An integral metatheory. United Kingdom: Routledge.

Ehnert, I. (2009). Sustainable human resource management. Springer Science \& Business Media: Berlin.

Elman, C. E. M. F. (2003). Progress in international relations theory: Appraising the field. United States: MIT Press.

Foster, R., \& Kaplan, S. (2011). Creative destruction: Why companies that are built to last underperform the market-and how to success fully transform them. Currency/Doubleday: New York.

Frye, T. (2000). Brokers and bureaucrats: Building market institutions in Russia. United States: University of Michigan Press.

Galbraith, J. R. (2008). Designing matrix organizations that actually work: How IBM, Proctor $\&$ Gamble and others design for success. United States: John Wiley \& Sons.

George, A. L., Bennett, A., Lynn-Jones, S. M., \& Miller, S. E. (2005). Case studies and theory development in the social sciences. United States: MIT Press.

Hargreaves, A. (2007). Sustainable leadership and development in education: Creating the future, conserving the past. European Journal of education, 42(2), 223-233.

Harrington, H. J. (2006). Process management excellence: The art of excelling in process management. Paton Press LLC, Chico, CA.

Haugh, H. M., \& Talwar, A. (2010). How do corporations embed sustainability across the organization? Academy of Management Learning E Education, 9(3), 384-396.

House, R. J., Spangler, W. D., \& Woycke, J. (1990). Personality and charisma in the US presidency: A psychological theory of leadership effectiveness. Administrative Science Quarterly, 36(1), 364-396.

Hoverstadt, P., \& Bowling, D. (2005). Organisational viability as a factor in sustainable development of technology. International Journal of Technology Management 8 Sustainable Development, 4(2), 131-146.

Hubbard, G., Pocknee, G., \& Taylor, G. A. (1996). Practical australian strategy. Prentice Hall Australia.

Johnson, G., Scholes, K., \& Whittington, R. (2010). Exploring corporate strategy: Text only. Pearson Education UK.

Johnson, G., Whittington, R., \& Scholes, K. (2009). Exploring corporate strategy with mystrategylab. Financial Times/Prentice Hall.

Kaplan, S. (2008). Cognition, capabilities, and incentives: Assessing firm response to the fiber-optic revolution. Academy of Management Journal, 51(4), 672-695.

Kasimoglu, M. (2006). An investigation into the death of organisations from old age in Turkey. European Business Review, 18(1), 14-32.

Khan, Z., Jawaid, S. T., Arif, I., \& Khan, M. N. (2012). Working capital management and firms profitability in Pakistan: A disaggregated analysis. African Journal of Business Management, 6(9), 3253-3261.

King, G., Keohane, R. O., \& Verba, S. (1994). Designing social inquiry: Scientific inference in qualitative research. United States: Princeton University Press.

Knoepfel, I. (2001). Dow Jones sustainability group index: A global benchmark for corporate sustainability. Corporate Environmental Strategy, 8(1), 6-15. 
Krippendorff, K. (2018). Content analysis: An introduction to its methodology. United States: Sage Publications.

Li, F. (2008). Annual report readability, current earnings, and earnings persistence. Journal of Accounting and Economics, 45(2-3), 221-247.

Linnenluecke, M., \& Griffiths, A. (2010). Beyond adaptation: Resilience for business in light of climate change and weather extremes. Business $\&$ Society, 49(3), 477-511.

Lubinski, C. (2011). Path dependency and governance in German family firms. Business History Review, 85(4), 699-724.

Maguire, E. R. (2003). Organizational structure in American police agencies: Context, complexity, and control. New York, United States: SUNY Press.

Martins, N., \& Coetzee, M. (2009). Applying the Burke-Litwin model as a diagnostic framework for assessing organisational effectiveness. SA Journal of Human Resource Management, 7(1), 1-13.

Mayfield, M., Mayfield, J., \& Stephens, D. (2007). The relationship of generic strategy typing and organizational longevity: A preliminary analysis in the comic book industry using the miles and snow typology. Competitiveness Review: An International Business Journal, 17(1/2), 94-108.

Miller, D., \& Hartwick, J. (2002). Spotting management fads. Harvard Business Review, $80(10), 26-7$.

Mitleton-Kelly, E. (2006). A complexity approach to co-creating an innovative environment. World Futures, 62(3), 223-239.

Montuori, L. (2000). Organizational longevity-integrating systems thinking, learning and conceptual complexity. Journal of Organizational Change Management, 13(1), 6173.

Morgan, N., Pritchard, A., \& Pride, R. (2011). Destination brands: Managing place reputation. United Kingdom: Routledge.

Nadler, D. A., \& Tushman, M. L. (1980). A model for diagnosing organizational behavior. Organizational Dynamics, 9(2), 35-51.

Palmer, I., Dunford, R., \& Akin, G. (2006). Managing organizational change. New York: McGraw-Hill.

Pawlowski, C. W. (2000). Comments on the use of propositional logic to examine sustainability concepts. Ecological Modelling, 127(2-3), 207-219.

Peters, T. J., Waterman, R. H., \& Jones, I. (1982). In search of excellence: Lessons from America's best-run companies. Harper Collins: London.

Porter, M. (1996). What is strategy? Harvard Business Review.

Porter, M. E., \& Kramer, M. R. (2006). The link between competitive advantage and corporate social responsibility. Harvard Business Review, 84(12), 78-92.

Raza, S. A., Jawaid, S. T., \& Hussain, A. (2014). Risk and investment decisions in stock markets: Evidence from four Asian countries. International Journal of Managerial and Financial Accounting, 6(3), 227-250.

Redmon, W. K., Mawhinney, T. C., \& Johnson, C. M. (2013). Handbook of organizational performance: Behavior analysis and management. United Kingdom: Routledge.

Rothaermel, F. T., \& Alexandre, M. T. (2009). Ambidexterity in technology sourcing: The moderating role of absorptive capacity. Organization Science, 20(4), 759-780. 
Sanchez, R. (2008). A focused issue on fundamental issues in competence theory development. Bingley, United Kingdom: Emerald Group Publishing Limited.

Schreier, M. (2012). Qualitative content analysis in practice. United States: Sage Publications.

Slager, R. (2015). Sri indices and responsible corporate behavior: A study of the FTSE4 good index. Business 85 Society, 54(3), 386-405.

Stacey, R. D. (1992). Managing the unknowable: Strategic boundaries between order and chaos in organizations. New York City, United States: John Wiley \& Sons.

Vannoni, M. (2015). What are case studies good for? Nesting comparative case study research into the Lakatosian research program. Cross-Cultural Research, 49(4), 331357.

Veider, V., \& Kallmuenzer, A. (2016). Assessing long-term orientation among founder-and descendant-led firms. Journal of Family Business Management, 6(1), 2-22.

Volgy, T. J., Sabic, Z., Roter, P., \& Gerlak, A. (2009). Mapping the new world order. Wiley Online Library.

Voss, G. B., \& Voss, Z. G. (2000). Strategic orientation and firm performance in an artistic environment. Journal of Marketing, 64(1), 67-83.

Wade, D., \& Recardo, R. (2009). Corporate performance management. United Kingdom: Routledge.

Waterman Jr, R. H., Peters, T. J., \& Phillips, J. R. (1980). Structure is not organization. Business Horizons, 23(3), 14-26.

Weisbord, M. R. (1976). Organizational diagnosis: Six places to look for trouble with or without a theory. Group \& Organization Studies, 1(4), 430-447.

Wolfram, H.-J., \& Mohr, G. (2009). Transformational leadership, team goal fulfillment, and follower work satisfaction: The moderating effects of deep-level similarity in leadership dyads. Journal of Leadership $\&$ Organizational Studies, 15(3), 260-274. 